\title{
Plasma cholesterol, coronary heart disease, and cancer in the Renfrew and Paisley survey
}

\author{
Christopher G Isles, David J Hole, Charles R Gillis, Victor M Hawthorne, Anthony F Lever
}

\begin{abstract}
The relation between plasma cholesterol concentration and mortality from coronary heart disease, incidence of and mortality from cancer, and all cause mortality was studied in a general population aged 45-64 living in the west of Scotland. Seven thousand men (yielding 653 deaths from coronary heart disease, 630 new cases of cancer, and 463 deaths from cancer) and 8262 women ( 322 deaths from coronary heart disease, 554 new cases of cancer, and 395 deaths from cancer) were examined initially in 1972-6 and followed up for an average of 12 years. All cause mortality was not related to plasma cholesterol concentration. This was largely a consequence of a positive relation between cholesterol values and mortality from coronary heart disease being balanced by inverse relations between cholesterol and cancer and between cholesterol and other causes of death. These changes were highly significant for coronary heart disease and cancer in men and significant for coronary heart disease and other causes of death in women. The inverse association between cholesterol concentration and cancer in men was strongest for lung cancer, was not merely a function of the age at which a subject died, was present for the incidence of cancer as well as mortality from cancer, and persisted when new cases or deaths occurring within the first four years of follow up were excluded from the analysis.
\end{abstract}

\section{Introduction}

The relation between plasma cholesterol concentration and mortality is complex. ${ }^{12}$ The plasma cholesterol concentration correlates positively with mortality from coronary heart disease, ${ }^{34}$ but some studies have shown a negative relation with death from cancer. ${ }^{5}$ If these two relations reflect causal mechanisms that are reversible by changing the plasma cholesterol concentration the benefits of lipid reduction for heart disease might be offset by an increase in mortality from cancer. In an attempt to analyse the problem further we have examined the relation between plasma cholesterol concentrations and coronary heart disease and cancer in a general population of 15399 middle aged men and women screened in Renfrew and Paisley from 1972 to 1976 and followed up until the end of 1986.

\section{Subjects and methods}

From 1972 to 1976,7053 men and 8346 women aged 45-64 attended a general health screening survey in Renfrew and Paisley. ${ }^{67}$ The survey in each town was preceded by a census; $79 \%$ of eligible subjects in Renfrew and $78 \%$ of those in Paisley attended. Total plasma cholesterol concentration was measured in venous blood samples from $7000(99 \cdot 2 \%)$ men and $8262(99.0 \%)$ women. Samples were taken without fasting and cholesterol measured by the method of Annan and Isherwood. ${ }^{8}$ All measurements of cholesterol concentration were done in the department of biochemistry, Royal Infirmary, Glasgow, and aliquots were tested, with satisfactory results, by an exchange of samples with the International Lipids Standardisation Laboratory at the Centers for Disease Control in Atlanta, Georgia. Smoking habits were recorded by a standard questionnaire. Blood pressure was measured with the London School of Hygiene sphygmomanometer, ${ }^{9}$ diastolic pressure being recorded at the disappearance of the fifth Korotkoff sound. Social class was determined from occupation in men; women were classified by the social class of their husbands or fathers. ${ }^{10}$ Record linkage of all subjects with the Registrar General in Scotland ensured that we were notified of a subject's death (provided that it occurred within the United Kingdom) and of the cause of death as classified by the registrar using the International Classification of Diseases (ICD). ${ }^{11}$ We had previously assessed these methods in a study of hypertensive patients, and subjects from the Renfrew and Paisley survey served as controls for that study. ${ }^{12}$ Notification from the Registrar General was virtually complete and comparison of coding of causes of death by the registrar and by independent physicians yielded no important discrepancies. ${ }^{12}$

A total of 1609 men and 1102 women had died by the end of 1986 during an average follow up.of 12 years. Six hundred and fifty three of the deaths in men were considered to be due to coronary heart disease and 463 to cancer. The corresponding figures for women were 322 deaths due to coronary heart disease and 395 to cancer. Age adjusted death rates were calculated as deaths $/ 1000$ patient years stratified by fifths of plasma cholesterol concentrations for all causes, ischaemic heart disease (ICD codes 410-414), cancer (140-208), and all other causes (all other codes). The quintile points (values separating fifths) for men were $5 \cdot 0,5 \cdot 6,6 \cdot 0$, and $6 \cdot 6 \mathrm{mmol} / \mathrm{l}(195,215,231$, and $254 \mathrm{mg} / \mathrm{dl})$ and for women $5 \cdot 5,6 \cdot 1,6 \cdot 6$, and $7 \cdot 2 \mathrm{mmol} / 1$ $(212,236,254$, and $280 \mathrm{mg} / \mathrm{dl})$. A proportional hazards mode ${ }^{13}$ was used to evaluate trends in mortality across the fifths of cholesterol values. The model included a quadratic term for cholesterol to test for non-linearity. Results are presented both as relative risks and as adjusted rates. The relative risk for each fifth of cholesterol was adjusted for the effects of age, body mass index, blood pressure, smoking habit, and social class and expressed as a ratio of the risk in the bottom fifth. The absolute rate for the bottom fifth was calculated, and the adjusted rates for the remaining fifths derived from the estimates of relative risk.

Additional information on the incidence of cancer was available because all new cancers developing in people in Renfrew and Paisley were registered with the cancer surveillance unit at Ruchill Hospital. Thus $\mathbf{6 3 0}$ new cancers in men and 554 new cancers in women had been registered between screening and the end of 1986, when our analysis began. In some of the analyses presented below age adjusted incidences of cancer, calculated as new cases per 1000 patient years by quintile of plasma cholesterol value and adjusted for other risks as above, are given together with the data on cancer mortality. 


\section{Results}

DISTRIBUTION OF PLASMA CHOLESTEROL CONCENTRATIONS AND RELATION TO OTHER RISKS

Table I shows the distribution of plasma cholesterol concentrations in the men and women studied. Mean values were higher in women $(6.43(\mathrm{SD} 1.09) \mathrm{mmol} / \mathrm{l})$ than in men $(5.87(0.96) \mathrm{mmol} / \mathrm{l}) ; 48 \%$ of the women $(3948 / 8262)$ and $26 \%$ of the men $(1839 / 7000)$ had plasma cholesterol concentrations of $6.5 \mathrm{mmol} / \mathrm{l}$ or greater. A large proportion of subjects of both sexes had other risk factors for vascular disease, including obesity, high blood pressure, cigarette smoking, and low social class. A total of 770 men $(11 \%)$ were grossly obese with a body mass index of greater than 30 , $2520(36 \%)$ had a diastolic pressure in excess of $90 \mathrm{~mm} \mathrm{Hg}$ at the screening examination, 3129 (45\%) smoked 15 or more cigarettes a day, and $4760(68 \%)$ belonged to social class IIIM, IV, or V. The corresponding figures for women were 1239 (15\%) obese, 2809 (34\%) hypertensive, 2314 (28\%) heavy smokers, and $4544(55 \%)$ low social class. Table II shows that men and women with high plasma cholesterol concentrations were more likely to be obese and to have high blood pressure, whereas subjects with low plasma cholesterol concentrations appeared to smoke heavily and be of low social class. Because of these relations and the possible influence that each might have on mortality death rates were adjusted not only for age but also for body mass index, blood pressure, smoking habit, and social class. The adjustment for smoking

TABLE I-Distribution of plasma cholesterol concentrations in men and women

\begin{tabular}{|c|c|c|c|c|c|}
\hline \multicolumn{2}{|c|}{ Plasma cholesterol ${ }^{\star}$} & \multicolumn{2}{|c|}{ Men } & \multicolumn{2}{|c|}{ Women } \\
\hline $\mathrm{mg} / \mathrm{dl}$ & $\mathrm{mmol} / \mathrm{l}$ & No & $\%$ & No & $\%$ \\
\hline$<150$ & $<3.9$ & 91 & $1 \cdot 3$ & 28 & 0.3 \\
\hline 150 & 3.9 & 106 & 1.5 & 52 & 0.6 \\
\hline $160-$ & $4 \cdot 1$ & 160 & $2 \cdot 3$ & 95 & $1 \cdot 1$ \\
\hline $170-$ & $4 \cdot 4$ & 266 & 3.8 & 151 & 1.8 \\
\hline $180-$ & $4 \cdot 7-$ & 416 & 5.9 & 253 & $3 \cdot 1$ \\
\hline $190-$ & $4 \cdot 9-$ & 531 & $7 \cdot 6$ & 326 & 3.9 \\
\hline $200-$ & $5 \cdot 2-$ & 782 & $11 \cdot 2$ & 490 & 5.9 \\
\hline $210-$ & $5 \cdot 4$ & 657 & $9 \cdot 4$ & 525 & $6 \cdot 4$ \\
\hline $220-$ & $5 \cdot 7$ & 798 & $11 \cdot 4$ & 806 & $9 \cdot 8$ \\
\hline $230-$ & $6 \cdot 0-$ & 835 & 11.9 & 899 & 10.9 \\
\hline $240-$ & $6 \cdot 2$ & 519 & $7 \cdot 4$ & 689 & $8 \cdot 3$ \\
\hline $250-$ & $6 \cdot 5-$ & 593 & $8 \cdot 5$ & 916 & $11 \cdot 1$ \\
\hline $260-$ & $6 \cdot 7-$ & 340 & 4.9 & 593 & $7 \cdot 2$ \\
\hline $270-$ & $7 \cdot 0-$ & 335 & $4 \cdot 8$ & 690 & $8 \cdot 4$ \\
\hline $280-$ & $7 \cdot 3-$ & 211 & $3 \cdot 0$ & 525 & $6 \cdot 4$ \\
\hline $290-$ & $7 \cdot 5=$ & 126 & 1.8 & 298 & 3.6 \\
\hline $300-$ & $7 \cdot 8-$ & 101 & 1.4 & 307 & 3.7 \\
\hline 310. & $8 \cdot 0-$ & 41 & 0.6 & 169 & $2 \cdot 0$ \\
\hline $320-$ & $8 \cdot 3-$ & 54 & 0.8 & 168 & $2 \cdot 0$ \\
\hline $330-$ & $8 \cdot 5$ & 15 & 0.2 & 95 & $1 \cdot 1$ \\
\hline & & 6 & $0 \cdot 1$ & 67 & 0.8 \\
\hline$\geqslant 350$ & $\geqslant 9 \cdot 1$ & 17 & 0.2 & 120 & $1 \cdot 5$ \\
\hline Total & & 7000 & $100 \cdot 0$ & 8262 & $100 \cdot 0$ \\
\hline
\end{tabular}

* Mean values (SD): men $227(37) \mathrm{mg} / \mathrm{dl}, 5.9(1 \cdot 0) \mathrm{mmol} / \mathrm{l}$; women 248 (42) $\mathrm{mg} / \mathrm{dl}, 6 \cdot 4(1 \cdot 1) \mathrm{mmol} / \mathrm{l}$.

TABLE II-Correlation coefficients between plasma cholesterol concentration and other risk factors in men and women

Body mass index Diastolic pressure Smoking habit Social class Plasma cholesterol

\begin{tabular}{|c|c|c|c|c|c|}
\hline \multicolumn{6}{|c|}{ Men } \\
\hline Age & -0.01 & 0.01 & -0.07 & 0.06 & 0.06 \\
\hline Body mass index & - & $0 \cdot 30$ & $-0 \cdot 18$ & -0.03 & $0 \cdot 15$ \\
\hline Diastolic pressure & - & - & $-0 \cdot 11$ & 0.00 & 0.07 \\
\hline Smoking habit & - & - & - & $0 \cdot 11$ & -0.04 \\
\hline Social class & - & - & - & - & $-0 \cdot 10$ \\
\hline \multicolumn{6}{|c|}{ Women } \\
\hline Age & $0 \cdot 11$ & $0 \cdot 15$ & $-0 \cdot 17$ & $0 \cdot 07$ & $0 \cdot 17$ \\
\hline Body mass index & - & 0.37 & -0.21 & $0 \cdot 11$ & 0.05 \\
\hline Diastolic pressure & - & - & $-0 \cdot 16$ & 0.05 & 0.08 \\
\hline Smoking habit & - & - & - & 0.07 & -0.04 \\
\hline Social class & - & - & - & - & -0.04 \\
\hline
\end{tabular}

Because of large numbers of subjects $r$ values greater than 0.04 were significant at $p<0.001$. included estimates of the intervening effect on mortality of each current smoking category-namely, 1-14 cigarettes a day, 15-24 cigarettes a day, 25 or more cigarettes a day, pipe and cigar smokers only, as well as ex-smokers - in relation to subjects who had never smoked regularly.

\section{PLASMA CHOLESTEROL AND MORTALITY}

All cause mortality was not significantly related to plasma cholesterol concentrations (fig 1). This was largely a consequence of a positive relation between cholesterol concentrations and mortality from coronary heart disease being balanced by inverse relations between cholesterol concentrations and cancer and between cholesterol concentrations and other causes of death. These changes were significant for coronary heart disease $(p<0.001)$ and cancer $(p<0.001)$ in men and for coronary heart disease $(p<0.01)$ and other causes of death $(p=0.02)$ in women.

Table III shows that the relative risk of a high plasma cholesterol concentration for coronary heart disease, determined by dividing the death rate in the top fifth of the cholesterol distribution by that in the bottom fifth, was 1.54 for men and 1.64 for women. Table III also shows the attributable risks of high cholesterol concentrations for coronary heart disease. We estimated that had the mortality from coronary heart disease in all subjects been the same as that in the lowest risk group $150(23 \%)$ fewer deaths from coronary heart disease would have been expected among men and 45 (14\%) fewer would have been expected among women. Similar results were obtained when men and women aged 45-54 and 55-64 at the time of screening were analysed separately (table III).

Further analyses were conducted of the negative relation between cholesterol concentrations and cancer. Analysis of the incidence of cancer at different sites in men disclosed a strong negative relation between cholesterol concentration and lung cancer $(\mathrm{p}<0.01)$, a non-linear ( $U$ shaped) relation between cholesterol concentration and colorectal cancer $(\mathrm{p}<0.01)$, and a negative relation between cholesterol concentration and cancers at other sites $(p<0.05)$. In women there was a significant non-linear (U shaped) relation for colorectal cancer $(p<0.05)$ but no consistent trends for cancers in lung, breast, or at other sites (fig 2).

The possibility that people with high cholesterol concentrations died prematurely from coronary heart disease, thereby depressing the mortality from cancer most in the highest fifth of the cholesterol distribution and least in the lowest fifth, may be discounted because the average age at death from cancer and from coronary heart disease was similar throughout the whole range of the plasma cholesterol distribution. In men the average age at death from cancer was 64.6 years at the bottom of the cholesterol distribution and 63.3 years at the top. The corresponding ages at death from coronary heart disease were 64.9 and 63.4 years. Similar results were obtained for women. Patients with high cholesterol concentrations did not therefore die earlier from coronary heart disease than from cancer.

Previous work has suggested that a low cholesterol concentration is a metabolic consequence of cancer present or unsuspected at the time of screening. ${ }^{14} \mathrm{We}$ therefore recalculated the incidence of and mortality from cancer after excluding all new cases and deaths from cancer occurring within the first four years of the study. The results, expressed as relative risk for top to bottom fifths, showed that the negative relation between cholesterol concentration and cancer in men persisted (table III) and that it remained particularly strong for lung cancer $(p<0.01)$. Similar results were obtained with and without data for the first four years 
when men aged 45-54 and 55-64 at the time of screening were analysed separately (table III).

We also considered the possibility that the negative relation between cholesterol concentration and cancer was a consequence of cigarette smoking. Had this been the case in the Renfrew and Paisley survey we should have expected plasma cholesterol concentrations to be lower in smokers. There was, however, no consistent relation (table IV). The trend towards lower plasma cholesterol concentrations in cigarette smokers noted in table II was thought to be due to the influence of the large number of men and women who smoked 15 to 24 cigarettes a day. Cholesterol concentrations were higher among people smoking more than this, suggesting no overall influence of smoking on plasma cholesterol values.

\section{Discussion}

The Renfrew and Paisley survey provided an unusual opportunity for an analysis of this sort. Advantages included the large number of people screened and the long duration of follow up. Record linkage with the Registrar General identified those who died in the United Kingdom and also gave causes of
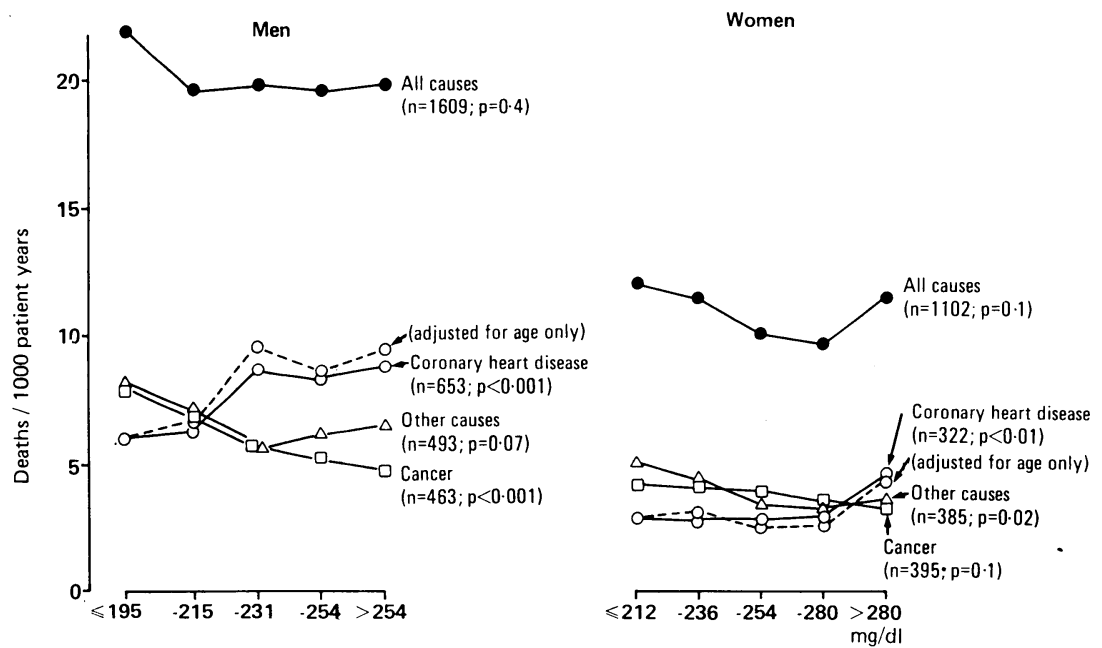

$\leqslant 5 \cdot 0 \quad-5 \cdot 6 \quad-6 \cdot 0 \quad-6 \cdot 6 \quad>6 \cdot 6$

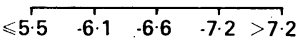

Plasma cholesterol

FIG 1-Deaths/1000 patient years in relation to plasma cholesterol values after adjusting for age, body mass index, diastolic blood pressure, smoking, and social class. Dashed line $(\bigcirc-\bigcirc)$ represents deaths from coronary heart disease adjusted for age only; additional adjustment for body mass index, diastolic pressure, smoking, and social class had little further effect. Best fit for each slope shown to be linear by logistic regression analysis, except for all cause mortality in women, which was curvilinear. $p$ Values refer to trends across fifths of plasma cholesterol concentrations death. Collaboration with the cancer surveillance unit at Ruchill Hospital provided data on the incidence of cancer as well as on mortality from cancer. There are advantages and disadvantages in using the Registrar General's data. ${ }^{15}$ The main advantages for our purpose were in completeness of data and consistency of classification. ${ }^{12}$ The main disadvantage was in accuracy of diagnosis. ${ }^{15}$ Our study was not an analysis in which clinical and postmortem data were assessed in every case by independent observers. For most decedents death and its cause were certified in the usual way by the general practitioner. This may reduce accuracy but it is highly unlikely to produce systematic bias in diagnosis. General practitioners completing the certificate were unaware that the data would be analysed in this way. The same could be said for the Registrar General in coding the cause of death. Because of the greater certainty of diagnosis and the independent check provided by the cancer registry our data for cancer are likely to be more reliable than those for ischaemic heart disease.

Our findings on the relation between cholesterol concentrations and coronary heart disease are similar to those reported elsewhere. ${ }^{34}$ Subjects in the top fifth of the cholesterol distribution in Renfrew and Paisley had a roughly $1 \cdot 5$-fold excess risk of coronary heart disease compared with subjects in the bottom fifth. Estimates of risk were based on large numbers of deaths and the risk gradient appeared continuous over the whole range of cholesterol concentrations in the survey. Relative risk was slightly lower and the overall mortality from coronary heart disease higher than in the Whitehall study ${ }^{3}$ and the multiple risk factor intervention trial, ${ }^{4}$ reflecting the inclusion of older people in our survey and the higher rates of coronary heart disease in the west of Scotland. ${ }^{16}$ Adjustment of coronary mortality for four widely accepted risk factors other than age also contributed to the lower relative risk of cholesterol concentrations for coronary heart disease in men (fig 1), but because serum cholesterol concentration correlated positively with obesity and blood pressure and negatively with smoking and social class (table II) the net effect of adjusting for all four risk factors was small. Our study also implies that a substantial number of deaths from coronary heart disease in Renfrew and Paisley might be prevented if plasma cholesterol concentrations could be lowered to those of men and women in the lowest fifth of risk. Evidence that lowering the plasma cholesterol concentration helps to reduce coronary risk has been provided by some ${ }^{1718}$ but not all ${ }^{19-21}$ dietary trials, and more recently by combined dietary and drug intervention. ${ }^{22-26}$

TABLE III - Risk analysis of plasma cholesterol concentrations in relation to coronary heart disease and cancer

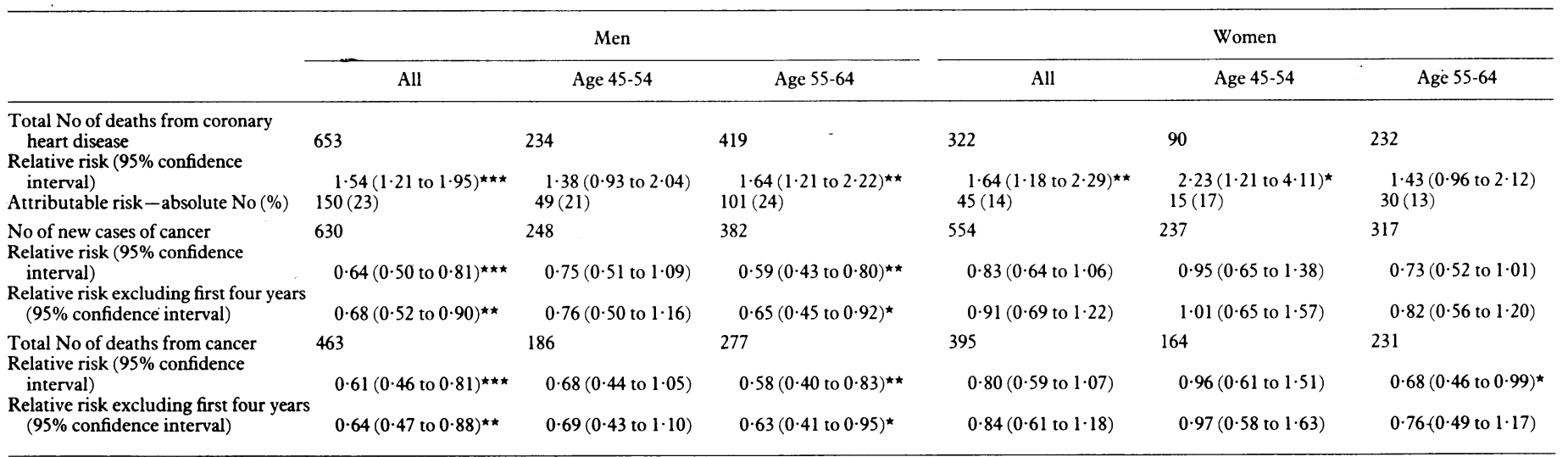

Relative risk for each slope calculated by dividing incidence or death rate in top fifth of cholesterol distribution by that in bottom fifth after fitting logistic regression model. All based on rates adjusted Relative risk for each slope calculated by dividing incidence or death rate in top fifth of cholesterol distribution by that in bottom fifth after fitting logistic regression model. All based on rates adjusted
for age, diastolic blood pressure, body mass index, smoking, and social class. Attributable risk calculated by subtracting coronary death rate of subjects in lowest fifth from coronary death rate in for age, diastolic blood pressure, body mass index, smoking, and social

each higher fifth, then multiplying by number
${ }^{\star} \mathrm{p}<0.05,{ }^{\star \star} \mathrm{p}<0.01,{ }_{\star}{ }^{\star} \mathrm{p}<0.001$ for trend. 


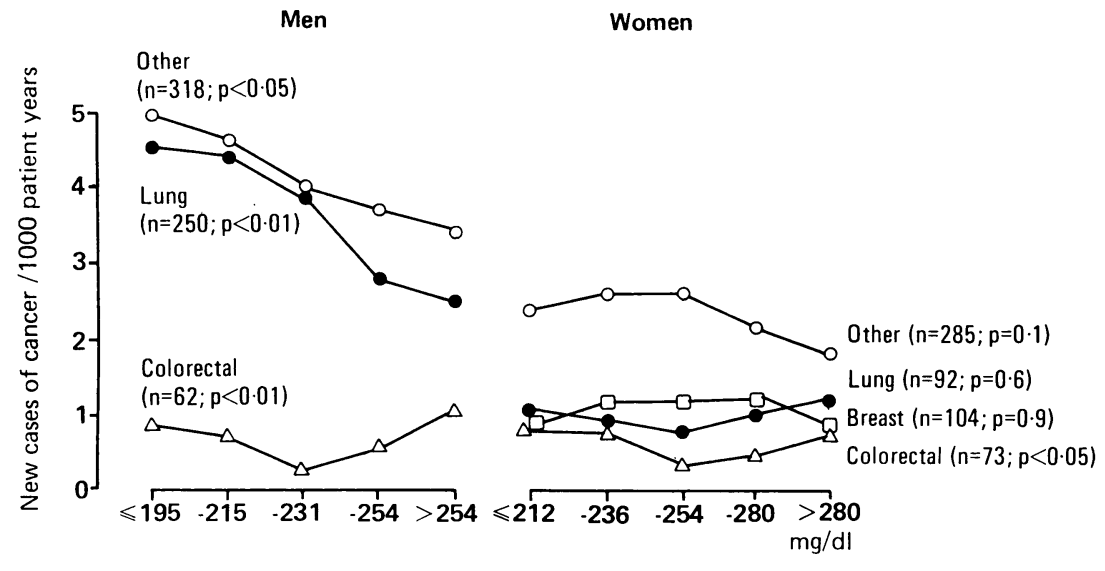

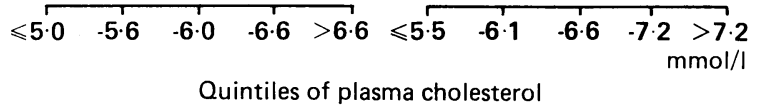

FIG 2-Incidence of cancer at different sites in relation to plasma cholesterol values. Rates expressed as new cases/1000 patient years after adjusting for age, body mass index, diastolic pressure, smoking, and social class. Inverse association between cholesterol concentration and cancer was strongest for lung cancer in men, even after adjustment for differences in smoking habits across the fifths of cholesterol

TABLE IV-Plasma cholesterol concentrations in smokers (mmol/l). Values are means (SD in parentheses)

\begin{tabular}{lcccccc}
\hline & & \multicolumn{5}{c}{ Cigarettes/day } \\
\cline { 3 - 6 } & Never smoked & $1-14$ & $15-24$ & $25-34$ & $\geqslant 35$ & Ex-smokers \\
\hline Men & $5 \cdot 87(1 \cdot 0)$ & $5 \cdot 78(1 \cdot 0)$ & $5 \cdot 78(0 \cdot 9)$ & $5 \cdot 87(1 \cdot 0)$ & $5 \cdot 91(0 \cdot 9)$ & $5 \cdot 98(1 \cdot 0)$ \\
No studied & 1175 & 830 & 2047 & 773 & 309 & 1726 \\
Women & $6 \cdot 48(1 \cdot 1)$ & $6 \cdot 40(1 \cdot 1)$ & $6 \cdot 37(1 \cdot 1)$ & $6 \cdot 30(1 \cdot 2)$ & $6 \cdot 42(1 \cdot 2)$ & $6 \cdot 48(1 \cdot 1)$ \\
No studied & 3775 & 1550 & 2001 & 261 & 52 & 617 \\
\hline
\end{tabular}

Table excludes 140 men and six women who smoked pipes or cigars.

More controversial than the positive relation between cholesterol concentration and coronary heart disease is the inverse association of cholesterol with cancer. ${ }^{5}$ Though this has been noted before (see below), several workers have argued that it is merely a metabolic consequence of a cancer present or undiagnosed at the time of screening,${ }^{14}$ a phenomenon referred to as the preclinical cancer effect. Our findings and those in some other studies do not support this. Among 21 reports there was no relation between serum cholesterol concentration and cancer in eight, ${ }^{27-32}$ an inverse association in $12,3^{33-44}$ and a positive relation for colorectal cancer in one. ${ }^{45} \mathrm{~A}$ preclinical cancer effect was considered to be the likeliest explanation in only four of the 12 studies showing an inverse association, ${ }^{35} 36{ }^{414}$ whereas the remaining eight groups of workers thought that their findings could not be explained in this way. ${ }^{33} 3437-404244$ In Renfrew and Paisley a preclinical cancer effect also seems unlikely. The negative relation between plasma cholesterol concentration and cancer was observed in both sexes, though it was significant only in men. It was present for the incidence of cancer as well as for mortality from cancer, and it persisted when new cases or deaths occurring within the first four years of follow up were excluded from the analysis. Cancers with the steepest negative relation were lung cancers in men. It seems unlikely that the cancer could affect cholesterol metabolism many years before these tumours became clinically apparent, but it is a possibility that we cannot exclude.

If a preclinical cancer effect is not responsible what alternative explanations exist? The possibility that people died at an earlier age from coronary heart disease than from cancer, thereby depressing the mortality from cancer most in the highest fifth and least in the lowest fifth of the cholesterol distribution may be discounted because the average age at death from cancer and from coronary heart disease was similar throughout the range of plasma cholesterol values.
This suggests that our findings are not merely a function of the age at which a person died.

Two other possibilities deserve consideration. The first is that a third "factor" independently causes both cancer and a low cholesterol concentration. In support of this it has been suggested that low concentrations of vitamin A predispose to cancer and that such patients have low cholesterol concentrations because of a shared deficiency in their binding proteins, respectively retinol binding protein and low density lipoprotein. ${ }^{46}$ Cigarette smoking is unlikely to be the third factor because the plasma cholesterol concentration was not consistently lower among smokers (table IV), and anyway our data (fig 2) were adjusted for the effects of cigarette smoking. The second possibility is that a low cholesterol concentration predisposes directly to cancer. Theoretically this is also possible. Cholesterol is an essential component of cell membranes. What is not clear is how far membrane cholesterol can be reduced without impairment of biological function and whether this would lead to an increased risk of malignancy. ${ }^{47}$

In summary there is good evidence from trials of treatment in men at high risk initially that reduction of plasma cholesterol by diet or drugs will lead to a reduction in coronary heart disease, ${ }^{17} 1822-26$ but it is also often the case that all cause mortality remains unchanged. ${ }^{48}$ This is unexpected if benefit for coronary heart disease is the only effect of lowering cholesterol concentration. In one instance a cholesterol lowering drug was shown to increase mortality from cancer, ${ }^{22}$ but otherwise there has been no significant excess of deaths from cancer in these trials. ${ }^{49}$ There is also, however, evidence from several longitudinal surveys of men and women in general populations, ${ }^{5}$ including our own, that cancers occur more commonly in people with low plasma cholesterol concentrations. These apparently conflicting claims are not necessarily contradictory, because the treatment trials were limited to men at high risk and the longitudinal surveys were studies of whole populations. The question whether reduction of plasma cholesterol within the normal range is associated with an increased risk of cancer has not, to our knowledge, been tested.

We conclude that it may be a mistake to assume that dietary advice given to the general population to reduce the intake of saturated fat will necessarily reduce overall mortality..$^{50}$ Coronary heart disease may well decrease but other risks might increase. The results of the Renfrew and Paisley survey and other work suggest that concentrating effort on people with the highest cholesterol concentrations is likely to be the wisest strategy ${ }^{5152}$ until more is known of the mechanisms underlying the risks associated with high and low cholesterol values.

This paper was presented in abstract form at the Scottish Society of Physician's meeting in Paisley, October 1987.

1 Consensus Conference. Lowering blood cholesterol to prevent heart disease. IAMA 1985;253:2080-6.

2 Ahrens EH. The diet-heart question in 1985: Has it really been settled? Lancet 1985;i:1085-9.

3 Rose G, Shipley M. Plasma cholesterol concentration and death from coronary heart disease: 10 year results of the Whitehall study. Br Med $\mathcal{F} 1986 ; 293$ : 306-7.

4 Martin MJ, Hulley SB, Browner WS, Kuller LH, Wentworth D. Serum cholesterol, blood pressure, and mortality: implications from a cohort of 361,662 men. Lancet 1986;ii:933-6.

5 McMichael AJ, Jensen OM, Parkin DM, Zaridze DG. Dietary and endogenous cholesterol and human cancer. Epidemiol Rev 1984;6:192-216.

6 Hawthorne VM, Greaves DA, Beevers DG. Blood pressure in a Scottish town. Br Med J 1974;iii:600-3.

7 Hawthorne VM. Epidemiology and treatment of hypertension in the community. Curr Med Res Opin 1977;5(suppl 1):109-14.

8 Annan W, Isherwood DM. An automated method for the direct determination of total serum cholesterol. Fournal of Medical and Laboratory Technolog 1969:26:202-11.

9 Rose GA, Holland WW, Crowley ${ }_{\eta}$ EA. A sphygmomanometer for epidemiologists. Lancet 1964;i: 296-300.

10 General Register Office. Classification of occupations 1966. London: HMSO, 1966. 
11 World Health Organisation. International classification of diseases. 9th Revision, 1975. Vol 1. Geneva: WHO, 1977.

12 Isles CG, Walker LM, Beevers GD, et al. Mortality in patients of the Glasgow blood pressure clinic. Fournal of Hypertension 1986;4:141-56.

13 Cox DR. Regression models and life tables. Journal of the Royal Statistical Society $(B)$ 1972;34: 187-220.

14 International Collaborative Group. Circulating cholesterol level and risk of death from cancer in men aged 40-69 years. FAMA 1982;248:2853-9.

15 Alderson MR, Bayliss RIS, Clarke CA, Whitfield AGW. Death certification. BrMed f 1983;287:444-5.

16 World Health Organisation. World health statistical annual 1986. Geneva: WHO, 1987 .

17 Leren P. The Oslo diet-heart study-11 year report. Circulation 1970;42: 935-42.

18 Turpeinen $\mathrm{O}$, Karvonen MJ, Pekkarinen M, Miettinen M, Elosuo R, Paavilainen E. Dietary prevention of coronary heart disease: the Finnish mental hospital study. Int $\mathcal{F}$ Epidemiol 1979;8:99-118.

19 Research Committee. Low fat diet in myocardial infarction: a controlled trial. Lancet 1965; ii:501-4.

20 Dayton S, Pearce ML, Goldman H, et al. Controlled trial of a diet high in unsaturated fat for prevention of atherosclerotic complications. Lance 1968;ii:1061-2

21 Medical Research Council Research Committee. Controlled trial of soya bean oil in myocardial infarction. Lancet 1968;ii:693-700.

22 Committee of Principal Investigators. A co-operative trial in the primary prevention of ischaemic heart disease using clofibrate. Br Heart $\mathcal{f}$ 1978;40: 1069-118.

23 Lipid Research Clinics Program. The lipid research clinics coronary primary prevention trial results. 1 . Reduction in incidence of coronary heart disease. JAMA 1984;251:351-64.

24 Canner PL, Berge KG, Wenger NK, et al. Fifteen year mortality in coronary drug project patients: long term benefit with niacin. $\mathcal{F}$ Am Coll Cardiol 1986;8:1245-55.

25 Blankenhorn DH, Nessim SA, Johnson RL, Sanmarco ME, Azen SP, Cashin-Hemphill L. Beneficial effects of combined colestipol-niacin therapy on coronary atherosclerosis and coronary venous bypass grafts. $尹 A M A$ 1987;257:3233-40.

26 Helsinki Heart Study. Primary prevention trial with gemfibrozil in middle aged men with dyslipidaemia. N Engl f Med 1987;317:1237-45.

27 Westlund $K$, Nicolaysen R. Ten year mortality and morbidity related to serum cholesterol. Scand f Clin Lab Invest 1972;30(suppl 127):3-24.

28 Dyer AR, Stamler J, Paul O, et al. Serum cholesterol and risk of death from cancer and other causes in three Chicago epidemiological studies. $f$ Chronic Dis $1981 ; 34: 249-60$

29 Yaari S, Goldbourt U, Evan-Zohar S, et al. Associations of serum high density lipoprotein and total cholesterol with total, cardiovascular and cance mortality in 7 year prospective study of 10,000 men. Lancet 1981;i:1011-4

30 Thomas CB, Duszynski KR, Schaffer JW. Cholesterol levels in young adulthood and subsequent cancer: a preliminary note. Johns Hopkins Medical foumal 1982;150:89-94.

31 Hiatt RA, Friedman GD, Bawol RD, et al. Breast cancer and serum cholesterol. $\mathcal{F} N C I$ 1982;68:885-9.
32 Salonen JT. Risk of cancer and death in relation to serum cholesterol: a longitudinal study in an eastern Finnish population with high overal cholesterol level. Am f Epidemiol 1982;116:622-30.

33 Kark GD, Smith AH, Hames CG. The relationship of serum cholesterol to the incidence of cancer in Evans County, Georgia. I Chronic Dis 1980;33: 311-22.

34 Beaglehole R, Foulkes MA, Prior IAM, et al. Cholesterol and mortality in New Zealand Maoris. Br Med f 1980;280:285-7.

35 Cambien F, Ducimetiere P, Richard J. Total serum cholesterol and cancer mortality in a middle aged male population. Am $\mathcal{F}$ E pidemiol 1980;112: 388-94.

36 Rose G, Shipley MJ. Plasma lipids and mortality, a source of error. Lancet $1980 ; 1: 523-6$

37 Williams RR, Sorlie PD, Feinleib M, et al. Cancer incidence by levels of cholesterol. FAMA 1981;245:247-52

38 Kozarevic D, McGee D, Vojvodic N, et al. Serum cholesterol and mortality: the Yugoslavian cardiovascular diseases study. Am $\mathcal{F}$ Epidemiol 1981;114: 21-8.

39 Garcia-Palmieri MR, Sorlie PD, Costas R, et al. An apparent inverse relationship between serum cholesterol and cancer mortality in Puerto Rico. Am f Epidemiol 1981;114:29-40.

40 Kagan A, McGee DL, Yano K, et al. Serum cholesterol and mortality in a Japanese-American population: the Honolulu heart program. $A m \mathcal{J}$ Epidemiol 1981;114:11-20.

41 Wallace RB, Rost C, Burmeister LF, et al. Cancer incidence in humans: relationship to plasma lipid and relative weight. $f N C I$ 1982;68:915-8.

42 Peterson B, Trelle E. Premature mortality in middle aged men: serum cholesterol as a risk factor. Klin Wochenschr 1983;63:795-801.

43 Hiatt RA, Fireman BH. Serum cholesterol and the incidence of cancer in a large cohort. $\mathcal{F}$ Chronic Dis 1986;39:861-70.

44 Schatzkin A, Hoover RN, Taylor PR, et al. Serum cholesterol and cancer in the NHANES I epidemiologic follow up study. Lancet 1987;ii:298-301.

45 Tornberg SA, Holm LE, Carstensen JM, Eklund GA. Risks of cancer of the colon and rectum in relation to serum cholesterol and beta lipoproteins. N Engl f Med 1986;315:1629-33.

46 Kark JD, Smith AH, Hames CG. Serum retinol and the relation between serum cholesterol and cancer. Br Med f 1982;284:152-4.

47 Oliver MF. Serum cholesterol-the knave of hearts and the joker. Lancet $1981 ;$ ii: $1090-5$.

48 Oliver MF. Reducing cholesterol does not reduce mortality. 7 Am Coll Cardiol 1988;12:814-7.

49 Ederer F, Leren $P$, Turpeinen $O$, Frantz ID. Cancer among men on cholesterol lowering diets. Lancet 1971;ii:203-6.

50 Report of WHO Expert Committee. Prevention of coronary heart disease. WHO Tech Rep Ser 1982; No 678 .

51 Oliver MF. Should we not forget about mass control of coronary risk factors? Lancet 1983;i:37-8.

52 British Cardiac Society Working Group on Coronary Prevention. Conclusions and recommendations. Br Heart $\mathcal{F}$ 1987; 57:188-9.

(Accepted 31 fanuary 1989)
Cavendish Clinic, 21 Wellington Road, London NW8 9SQ

J C Stevenson, MRCP, consultant endocrinologist B Lees, BSC, scientific officer M Devenport, MB, clinical research assistant

M P Cust, MRCOG, clinical research fellow

K F Ganger, MRCOG, clinical research fellow

Correspondence to: $\mathrm{Dr}$ Stevenson.

BrMed $\mathcal{J}$ 1989;298:924-8

\section{Determinants of bone density in normal women: risk factors for future osteoporosis?}

\author{
J C Stevenson, B Lees, M Devenport, M P Cust, K F Ganger
}

important. None, however, could predict satisfactorily women at future risk for osteoporosis.

Direct measurements of bone density in the clinically relevant sites are necessary to determine which women should receive preventive treatment for postmenopausal osteoporosis. This would help make such treatment more cost effective.

\section{Introduction}

Two main factors determine a woman's susceptibility to postmenopausal osteoporosis. Firstly, there is the peak adult bone mass attained, and secondly, there is the subsequent bone loss. A primary cause of bone loss is the decline of ovarian function associated with the menopause. ${ }^{1-4}$ It has been proposed, however, that osteoporosis of the proximal femur is not a direct result of the menopause. ${ }^{5}$ Controversy also exists as to when the peak adult bone mass is attained and whether appreciable loss of bone occurs before the menopause. ${ }^{16-9}$ In addition, the importance of the influence of certain lifestyle factors on the skeleton, and whether increased risk for osteoporosis can be predicted from these, is not established. The ability to predict the occurrence of osteoporosis is all important for selecting patients for preventive treatment so that unnecessary treatment can be avoided. 